\title{
Avaliação da resistência de progênies de Eucalyptus grandis para mancha foliar de Cylindrocladium e Kirramyces
}

\author{
Eduardo Henrique Rezende ${ }^{1} \oplus$, Izabela Moura Duin $^{1} \oplus$, Thiare Aparecida do Valle Coelho ${ }^{1} \oplus$, Izabele Domingues

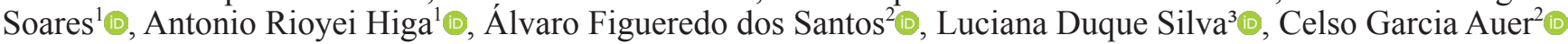

${ }^{1}$ Universidade Federal do Paraná, UFPR, Av. Pref. Lothário Meissner, no 900, Jardim Botânico, CEP 80210-170, Curitiba, PR, Brasil; ${ }^{2}$ Embrapa Florestas, Colombo, PR, Brasil. Estrada da Ribeira, Km 111 - Parque Monte Castelo, CEP 83411-000, Colombo, PR, Brasil. ${ }^{3}$ Escola Superior de Agricultura Luiz de Queiroz, Av. Pádua Dias, nº 11, CEP 13418-260, Piracicaba, SP, Brasil.

Autor para correspondência: Eduardo Henrique Rezende (eduardo.h.r@hotmail.com)

Data de chegada: 22/02/2018. Aceito para publicação em: 06/03/2019.

\section{RESUMO}

Rezende, H.E.; Auer, C.G.; Higa, A.R.; Santos, A.F. dos; Silva, L.D.; Duin, I.M.; Coelho, T.A.V.; Soares, I.D. Avaliação da resistência de progênies de Eucalyptus grandis para mancha foliar de Cylindrocladium e Kirramyces. Summa Phytopathologica, v.45, n.3, p.295-301, 2019.

Durante o cultivo do eucalipto existem várias doenças que podem limitar sua produtividade, tal como as manchas foliares causadas por Cylindrocladium spp. e Kirramyces epicoccoides. Assim, este trabalho teve como objetivo avaliar a resistência de progênies de Eucalyptus grandis a estas doenças. O teste de progênie com 176 progênies e três testemunhas comerciais para comparação foi instalado em dois locais: Anhembi e Itatinga, estado de São Paulo, Brasil. As avaliações de incidência e severidade de mancha foliar foram realizadas, aos 12 e 24 meses de idade (Anhembi) e aos 15 e 27 meses de idade (Itatinga). A severidade foi avaliada com uma escala que variou de um (sadia) a cinco (desfolha até $2 / 3$ da copa). A incidência e severidade média obtida pelas progênies foram comparadas com as testemunhas (variedades comerciais) e entre locais. Foi realizado também a espacialização da doença nas áreas do teste. Algumas progênies apresentaram severidade média menor às testemunhas comerciais, indicando potencial para uso em programas de melhoramento para resistência à mancha foliar. Existe variação entre as progênies em relação a resistência a mancha foliar, logo a possibilidade de se obter ganhos com a seleção entre as melhores progênies.

Palavras-chave: doença foliar, eucalipto, fungos.

\section{ABSTRACT}

Rezende, H.E.; Auer, C.G.; Higa, A.R.; Santos, A.F. dos; Silva, L.D.; Duin, I.M.; Coelho, T.A.V.; Soares, I.D. Evaluation of resistance in Eucalyptus grandis progenies against leaf spot of Cylindrocladium and Kirramyces. Summa Phytopathologica, v.45, n.3, p.295-301, 2019.

During cultivation of eucalyptus, there are several diseases, which can limit its productivity, such as leaf spots caused by Cylindrocladium spp. and Kirramyces epicoccoides. Therefore, the objective of this study was to evaluate the resistance of Eucalyptus grandis progenies to these diseases. A progeny test with 176 progenies and three commercial controls for comparison was installed in two locations: Anhembi and Itatinga, São Paulo State, Brazil. Leaf spot incidence and severity were evaluated when plants were 12 and 24 months old (Anhembi) and 15 and 27 months old (Itatinga). Severity was evaluated based on a scale varying from one (healthy) to five (up to $2 / 3$ canopy defoliation). The incidence and mean severity obtained by progenies were compared to those of controls (commercial varieties) and between locations. Spatialization of the disease was also performed in the test areas. Some progenies had mean severity lower than that of commercial controls, indicating potential for use in breeding programs for resistance to leaf spot. There is variation among the progenies in relation to resistance to leaf spot and consequently possibility of gaining with the selection among the best progenies.

Keywords: foliar disease, eucalyptus, fungi.

As espécies do gênero Eucalyptus são as mais plantadas no Brasil, com cerca de 5,7 milhões hectares plantados (12). Porém, existe uma série de fatores adversos associados ao cultivo intensivo de eucalipto, que podem afetar e diminuir a sua produtividade, com destaque especial para as doenças $(2,7,8$, 9), destacando-se as manchas foliares (5).

A mancha foliar é caracterizada pela colonização da folha por fungos e consequentemente desfolha, reduzindo a área fotossintética, afetando o crescimento das plantas, além de aumentar a infestação da área por plantas invasoras, ocasionada pela maior entrada de luz no plantio devido à desfolha das árvores $(2,5)$

Em espécies florestais, o controle da mancha foliar em campo é feito por meio da utilização de espécies resistentes. A resistência das diferentes espécies de eucalipto a mancha foliar varia entre e dentro de espécies (13).
A resistência de uma planta a uma doença é a capacidade que uma planta tem de impedir ou retardar a entrada e/ou outras atividades do patógeno em seu próprio tecido, seja por um meio estrutural ou bioquímico (2). Por isso, as plantas mais resistentes às doenças têm maiores condições de se adaptar melhor ao ambiente e de ter alto potencial produtivo.

A resistência de uma planta a determinada doença pode ser avaliada utilizando as variáveis incidência e severidade. Na quantificação da incidência, é verificada a presença ou ausência da doença em cada indivíduo, e expressa em porcentagem do número total de indivíduos com doença em relação ao número total de indivíduos. A incidência tem maior relevância na seleção para resistência quando a doença atinge diretamente o produto final $(2,4)$.

A severidade é um método de se quantificar a doença mais preciso em relação à incidência quando se fala de resistência, pois ela reflete na realidade o 
grau dos danos que estão ocorrendo na planta devido à ação do patógeno, além de caracterizar melhor o nível de resistência e expressar a intensidade da doença (4).

O melhoramento visando resistência a doenças é uma atividade constantemente relatada para a espécie E. grandis, Eucalyptus grandis Hill (ex Maiden), no estado de São Paulo. Este estado possui condições climáticas favoráveis para o desenvolvimento de doenças foliares causadas por fungo, como é o caso da mancha foliar. Silva et al. (22) citam em um trabalho visando resistência de E. grandis a ferrugem (Puccinia psidii), que o clima do estado é favorável ao desenvolvimento desta doença, que possui características de disseminação e formação de epidemias semelhantes as manchas foliares.

Assim este trabalho teve como objetivo analisar como ocorre a mancha foliar em um teste de progênies, e verificar o potencial de uso das progênies de E. grandis visando a resistência a esta doença.

\section{MATERIAL E MÉTODOS}

Caracterização da área experimental

O teste foi instalado nas estações experimentais da Escola Superior de Agricultura "Luiz de Queiroz" (ESALQ/USP) nos munícipios de Anhembi (agosto/2014) e Itatinga (maio/2014), estado de São Paulo. Itatinga está localizada mais ao sul e possui maior altitude em relação a Anhembi. O clima das duas regiões é classificado como Cfa segundo Koppen (3). Os dados climáticos históricos indicam que em Itatinga as temperaturas são inferiores e a precipitação é maior em relação a Anhembi (21).

Para avaliar os possíveis fatores ambientais que podem ter contribuído para a infecção de patógenos e desenvolvimento de doenças nas áreas estudadas, foram coletados dados meteorológicos de temperaturas média, mínima, máxima e umidade relativa, precipitação, no período de 01/05/2014 à 31/01/2017. Os dados foram coletados em estações meteorológicas localizadas nas estações experimentais onde foram instalados os testes de progênies (Figura 1).

A
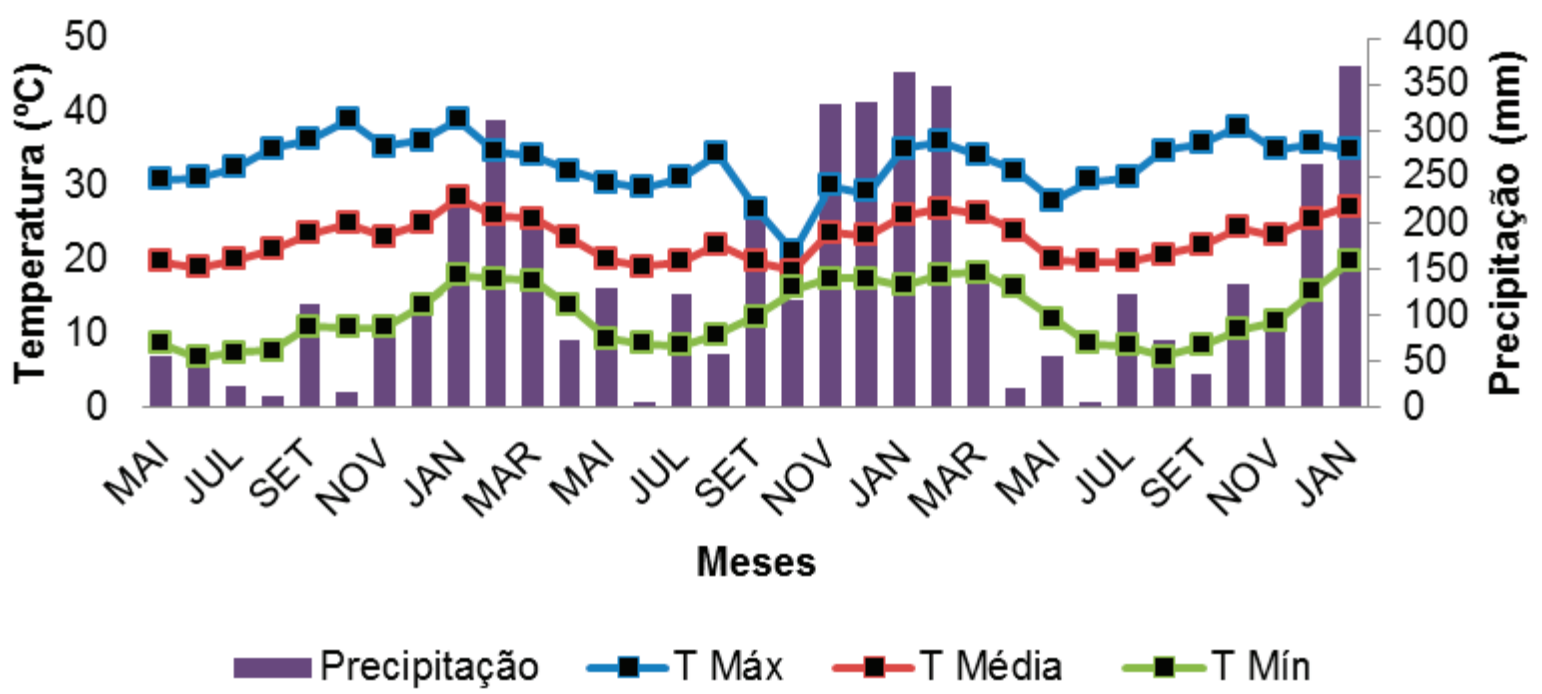

B

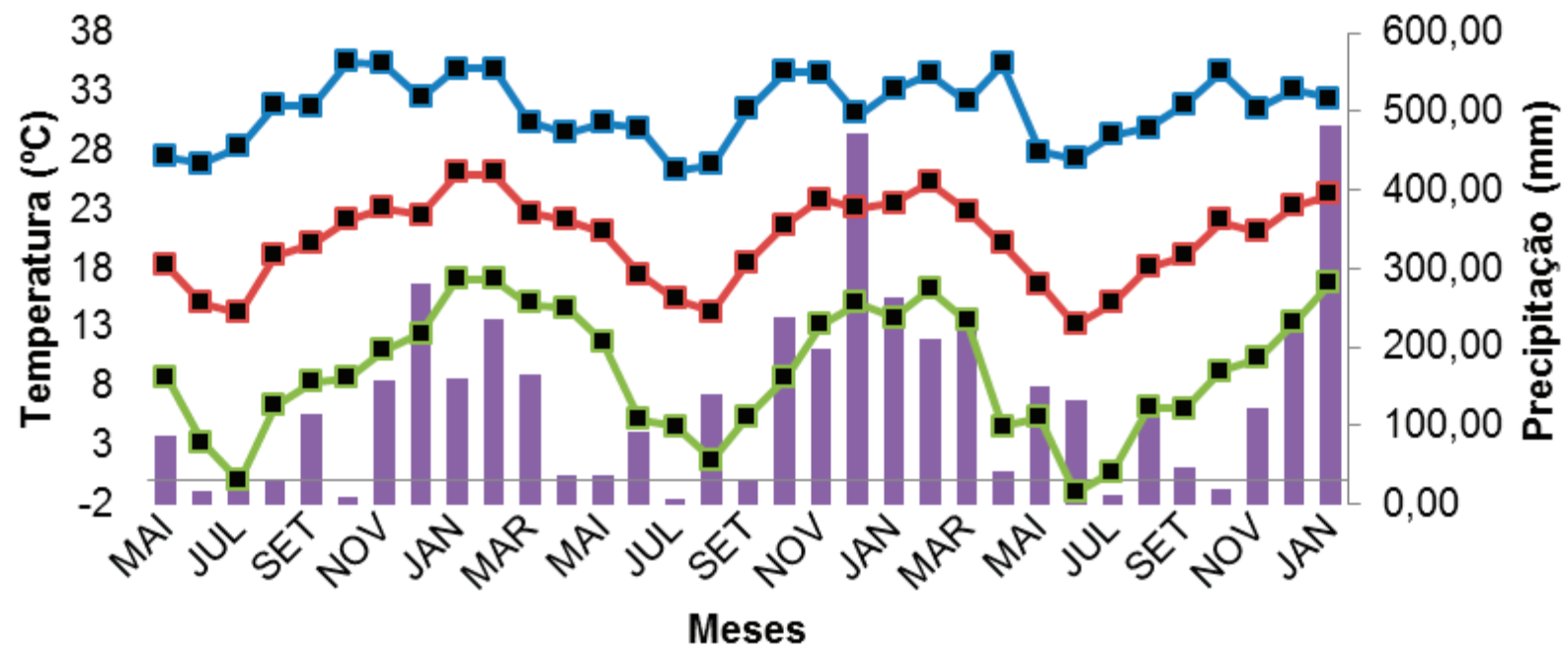

Precipitação $\quad \rightarrow$-T Máx $\quad \rightarrow-T$ Média $\quad$-T Mín

Figura 1. Climatograma da temperatura média, mínima, máxima e precipitação, nos meses de maio/2014 a janeiro/2018. (A): Estação meteorológica da estação

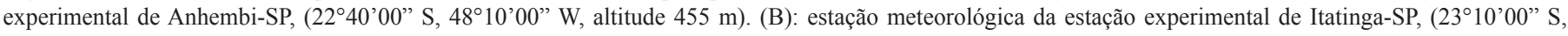
$48^{\circ} 40^{\prime} 00^{\prime}$ W, altitude $850 \mathrm{~m}$ ) 


\section{Delineamento experimental}

O delineamento experimental utilizado nos testes foi blocos ao acaso, cada teste foi implantado com 176 progênies de E. grandis, oriundas de um Pomar Clonal localizado em Itapeva-SP, mais três testemunhas: um clone comercial de Eucalyptus urophylla (Clone I 144), mudas seminais produzidas a partir de lote de sementes comerciais oriundo de uma Área de Produção de Sementes de $E$. grandis em Itatinga-SP e outro a partir de lote de sementes comerciais oriundo de Pomar de Sementes por Mudas de E. grandis de Anhembi-SP.

Ambas as testemunhas seminais têm a origem em Coff's Harbour, no estado de New South Wales, na Austrália, e são oriundas de unidades produtoras de sementes localizadas nas próprias regiões do teste, e que passaram por etapas de melhoramento genético. O clone I 144 foi escolhido por ser um clone de alta produtividade e plantado em diferentes regiões do Brasil, inclusive nas regiões do teste.

As 176 progênies de E. grandis testadas são provenientes de matrizes selecionadas em plantios realizados com mudas feitas de sementes oriundas da

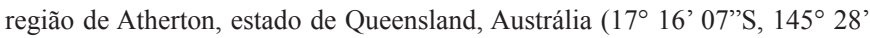
$30^{\prime \prime}$ 'E), região mais tropical comparada com Coff's Harbour ( $30^{\circ} 17^{\prime} 46^{\prime \prime} \mathrm{S}, 153^{\circ}$ 06'48”'E). O material genético de E. grandis com origem em Coff's Harbour geralmente é indicado para plantios no estado de São Paulo.

Foram utilizadas 30 repetições em Itatinga e 28 repetições em Anhembi, de uma planta por parcela. O plantio foi realizado em espaçamento $3 \times 2 \mathrm{~m}$, com duas linhas de bordadura externa.

\section{Isolamento e identificação dos fungos}

Folhas com sintomas de mancha foliar foram coletadas, para confirmação dos patógenos causadores. As amostras foram embaladas em sacos plásticos e enviadas ao laboratório

Foram feitos isolamentos diretos e indiretos de acordo com os padrões propostos por Alfenas et al. (1). No isolamento direto as amostras foram incubadas em câmara úmida utilizando gerbox com papel filtro umedecido com água ultrapurificada, com iluminação ambiente, até a formação de estruturas reprodutivas.

O isolamento indireto foi realizado por meio da desinfestação de fragmentos das folhas amostradas com álcool $70 \%$ por $30 \mathrm{~s}$ e hipoclorito de sódio $1 \%$ por 1 min, em seguida os fragmentos foram plaqueados em placas de Petri. Foram utilizados dois meios de culturas no plaqueamento: meio de cultura BDA $(39 \mathrm{~g}$ de extrato comercial de batata-dextrose-ágar, $1000 \mathrm{~mL}$ de água ultrapurificada). As placas foram incubadas em câmara B.O.D, no escuro a $24^{\circ} \mathrm{C}$, até a formação de colônias.

Para a identificação dos fungos isolados de forma direta e indireta, realizou-se a preparação de lâminas coradas com corante de Amann e através da observação microscópica foi realizada a identificação ao nível de gênero, com base em descrições e chaves sistemáticas $(2,6,7,10)$.

\section{Coleta e análise de dados}

A incidência e severidade da mancha foliar foram quantificadas em duas avaliações: aos 12 e 24 meses de idade (Anhembi) e aos 15 e 27 meses de idade (Itatinga). Na avaliação de incidência foi observado se havia presença ou ausência de sintomas das doenças nas plantas avaliadas e para a severidade foi utilizado uma escala de avaliação visual de acordo com Schultz $(19,20)$. Para a quantificação da severidade da mancha foliar foram atribuídas notas de 1 a 5 de acordo com a intensidade de desfolha observada (Figura 2). Foram consideradas somente as plantas vivas.

Para facilitar a compressão os valores das notas da escala de severidade de mancha foliar foram invertidos, a nota 5 passou a ser o valor de menor severidade e a nota 1 o maior valor. Deste modo, o aumento da severidade da doença ocorre com a diminuição do valor da nota de severidade, quanto maior for o valor obtido por um indivíduo maior será a resistência deste a doença

A incidência e severidade médias apresentadas pela população formada com as progênies de $E$. grandis foram comparadas com as das três testemunhas, em cada local, para verificar o potencial da população testada em relação à resistência a mancha foliar. Também foi verificada a posição média relativa das testemunhas no "ranking" com as severidades médias obtidas por cada progênie. Deste modo pode ser verificado a presença de progênies de E. grandis com desempenho superior ao das testemunhas.

Foi realizado a distribuição das progênies em mapas de espacialização de acordo com as classes de severidade. A produção dos mapas de espacialização foi produzida utilizando-se sistemas de informações geográficas com o auxílio do programa ArcGIS - versão 10.3.

Ao analisar a espacialização da doença entre e dentro blocos em Anhembi, o teste foi dividido em duas áreas, uma com 18 blocos, onde na segunda avaliação

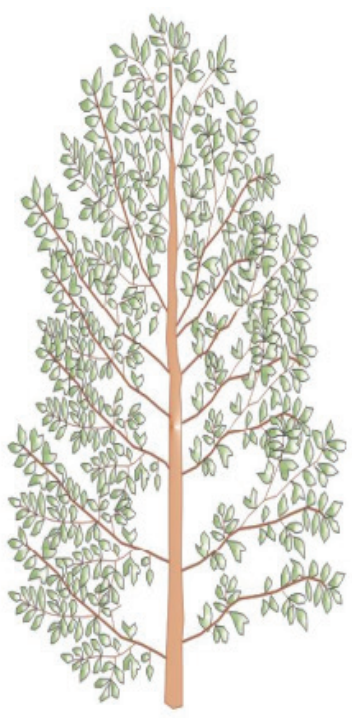

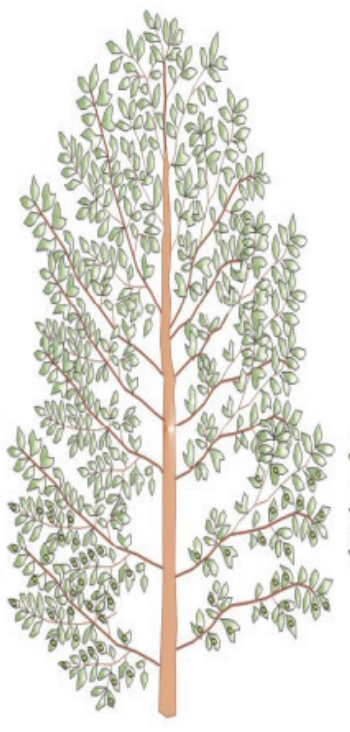

2

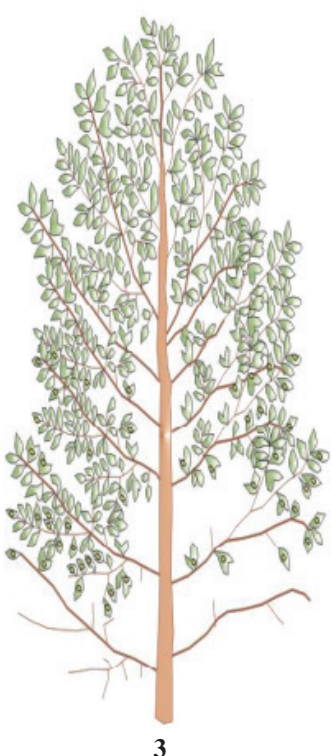

3
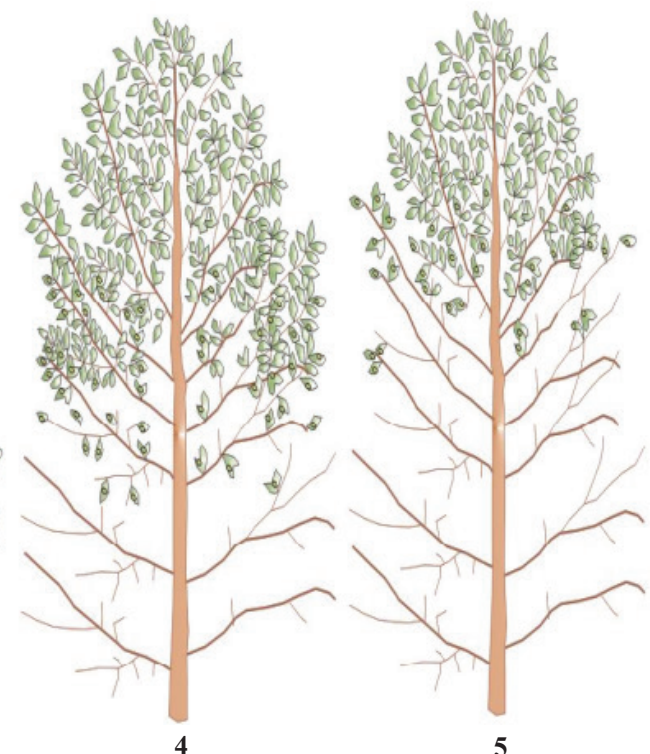

5

Figura 2. Escala de avaliação da severidade de manchas foliares em eucalipto. Escala de notas: 1 (plantas sadias), 2 (ausência de desfolha e presença de manchas foliares nos galhos inferiores), 3 (desfolha até $1 / 3$ da árvore), 4 (desfolha até 1/2 da árvore), 5 (desfolha até 2/3 da árvore). Adaptado de Schultz (15). 
somente 14 foram usados na espacialização, e outra com 10 blocos. Em Itatinga, os 30 blocos estavam agrupados no mesmo talhão.

Para verificar os efeitos das progênies foram realizadas duas avaliações em cada local, e os dados foram analisados aplicando o teste da razão de verossimilhança, utilizando o software SELEGEN REML/BLUP® $(17,19$, 23). Foi utilizado o modelo recomendado por Resende (18) na avaliação de indivíduos em progênies de meios-irmãos, no delineamento em blocos ao acaso, com uma planta por parcela, em um local sem medida repetida: $\mathrm{y}=\mathrm{Xr}+\mathrm{Za}+\mathrm{e}$.

\section{RESULTADOS E DISCUSSÃO}

Em ambos os locais, e em todas as avaliações, foi detectada a presença de mancha foliar. Nos isolamentos foram confirmados os fungos Cylindrocladium sp. e Kirramyces epicoccoides (Cooke e Massee) associados às manchas foliares em Itatinga-SP e Anhembi-SP.

Ao analisar a espacialização da doença em Anhembi, verificou-se que não houve a ocorrência de focos isolados da doença e uniformidade na distribuição da doença entre e dentro dos blocos, nas duas avaliações (Figura 3). Em Itatinga, a mancha foliar também ocorreu de forma similar: uniforme entre e dentro dos blocos, nas duas avaliações (Figura 4).
Em ambos os locais e em todas as avaliações, foram observados sintomas de mancha foliar caracterizados pela presença de lesões nas folhas e desfolha dispostas nas folhas na parte mais baixa da copa, que se estendiam até $2 / 3$ da copa da árvore.

Na primeira avaliação, as plantas apresentavam na sua maioria mancha foliar e desfolha na parte mais baixa da copa, enquanto que na segunda avaliação houve aumento do número de plantas com desfolha até a parte superior da copa. Este fato pode ser observado no aumento do número de plantas na classe $1 \mathrm{de}$ severidade (desfolha até $2 / 3$ da árvore), representada pela cor vermelha nas Figuras 3 e 4. Este comportamento foi descrito também por Taole et al. (24) com a mancha foliar de Mycosphaerella em Eucalyptus globulus Labill., onde a doença pode progredir no sentido da base para as partes mais altas da planta ao longo do tempo.

A desfolha ocasionada pela mancha foliar ocorre em função do aumento no número e no tamanho das lesões nas folhas, gerando perda de sustentação das folhas. Graça (11) verificou correlação significativa $(r>0,8)$, entre a desfolha e a área foliar lesionada em clones de E. grandis x E. urophylla afetados por mancha foliar de Cylindrocladium pteridis Wolf, indicando esta alta associação entre as duas variáveis na avaliação da severidade de mancha foliar.

Foi verificada alta incidência de mancha foliar (acima de 96\%) nas duas avaliações, nas duas áreas. As progênies de $E$. grandis apresentaram incidência
A

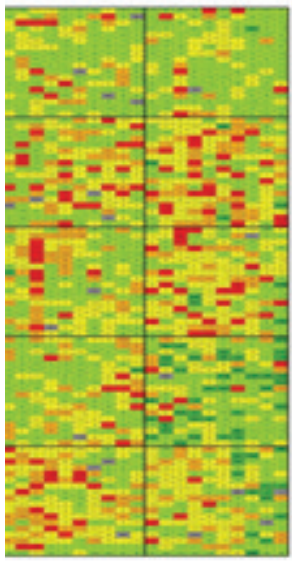

B

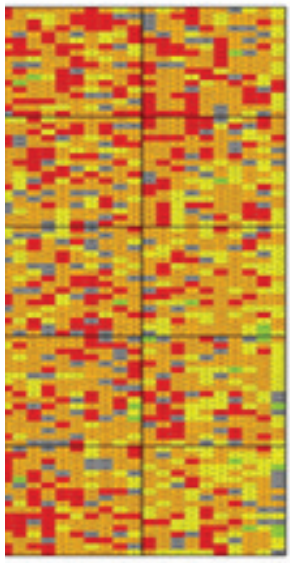

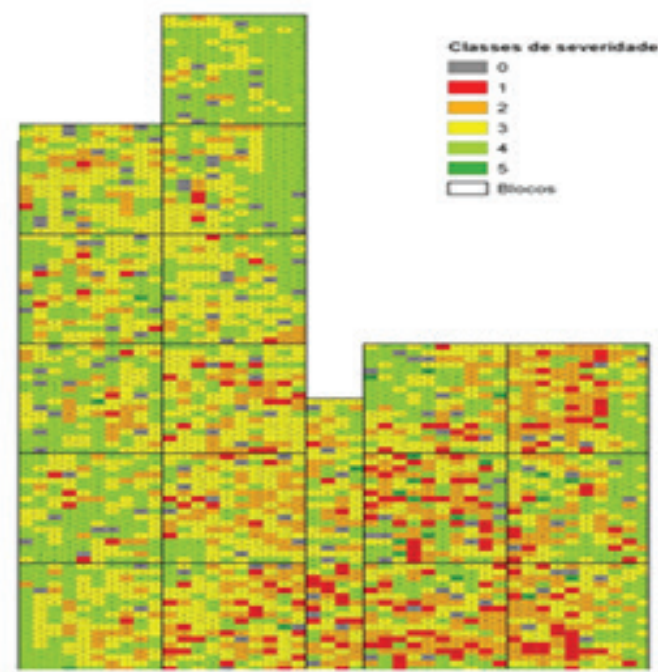

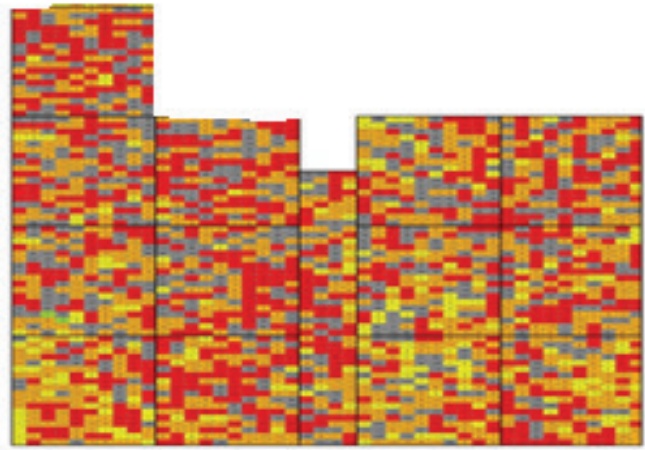

Figura 3 - Mapas de espacialização das plantas com sintomas de mancha foliar, em Anhembi-SP. (A) avaliação aos 12 meses; (B) avaliação aos 24 meses. Escala de notas: 5 (plantas sadias), 4 (ausência de desfolha e presença de manchas foliares nos galhos inferiores), 3 (desfolha até 1/3 da árvore), 2 (desfolha até 1/2 da árvore), 1 (desfolha até $2 / 3$ da árvore). 
A

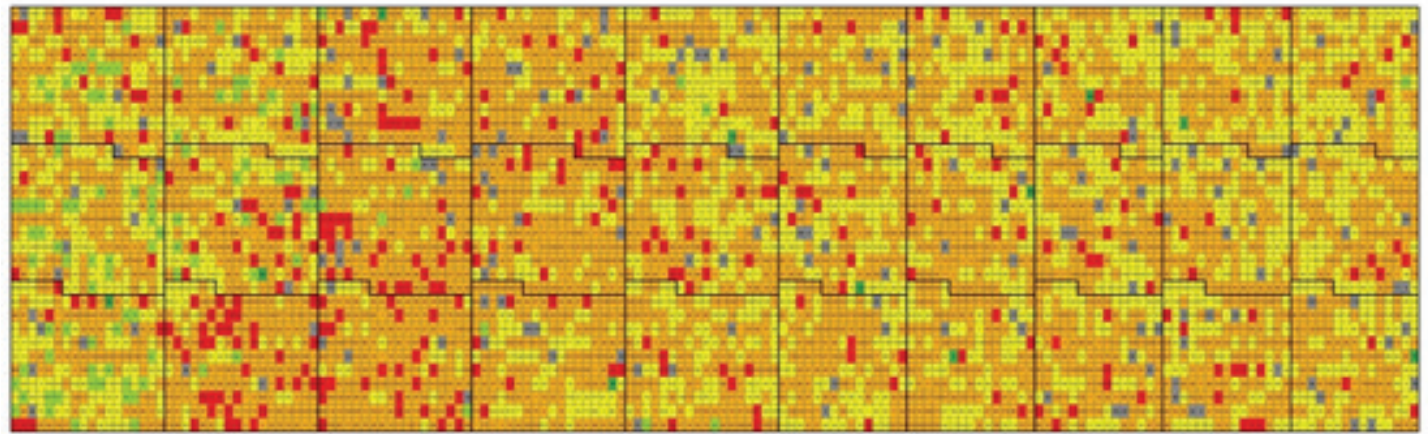

Classes de severidade

B
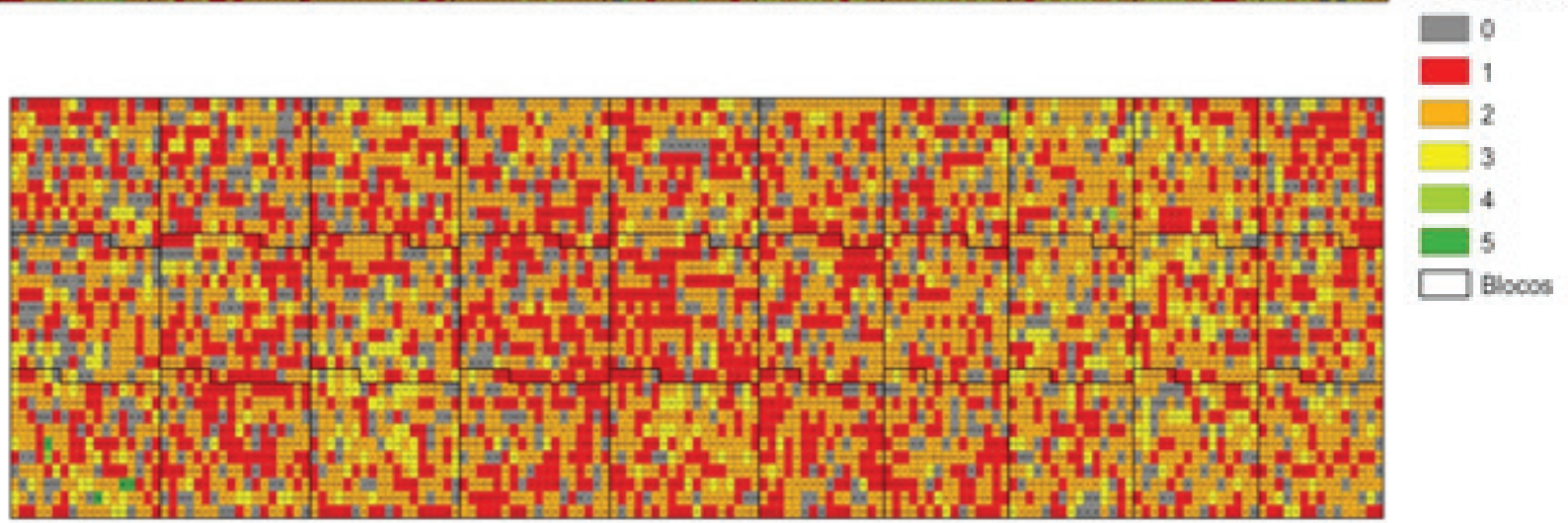

Figura 4. Mapas de espacialização das plantas com sintomas de mancha foliar, em Itatinga-SP. (A) avaliação aos 15 meses; (B) avaliação aos 27 meses. Escala de notas: 5 (plantas sadias), 4 (ausência de desfolha e presença de manchas foliares nos galhos inferiores), 3 (desfolha até 1/3 da árvore), 2 (desfolha até $1 / 2$ da árvore), 1 (desfolha até $2 / 3$ da árvore).

média de mancha foliar semelhante as testemunhas e sem grandes diferenças quanto ao local e época de avaliação (Tabela 1).

No caso das manchas doenças foliares, as avaliações de incidência não têm muita relevância para a seleção dos indivíduos mais resistentes, pois apesar de determinadas plantas apresentarem a presença do patógeno, a severidade da doença pode ser diferente em cada planta, ocasionando menores danos em alguns indivíduos.

A severidade média de mancha foliar obtida pelas progênies de $E$. grandis foi semelhante às testemunhas nos dois locais, e nas duas avaliações (Tabela 2). Em relação às duas épocas de avaliação, observou-se o progresso da doença, ou seja, o aumento na severidade na segunda avaliação em comparação com a primeira, este fato é possível de ser observado no aumento da severidade média apresentada na primeira avaliação em comparação com a segunda. Esta forma de progresso na severidade da doença também foi relatada por Schultz et al. (20), ao estudarem a severidade da mancha foliar de $C$. candelabrum em plantios de E. benthamii em diferentes idades, os autores verificaram severidade de 2,7 e 1,2, em uma escala de 0 a 4 , aos 18 meses e 8 meses de idade respectivamente.

Os efeitos da mancha foliar e desfolha causadas por Mycosphaerella em plantas de E. globulus, podem chegar à redução de biomassa de até 8 Kg em árvores atacadas por espécies de Mycosphaerella, aos 27 meses de idade, quando a severidade foi de $65 \%$ (13). Em plantas mais jovens também ocorre redução de biomassa em função da desfolha $(14,25)$. Krugner et al. (13) relataram redução no volume de diferentes espécies de Eucalyptus com a desfolha causada por Cylindrocladium spp. com o aumento do nível de severidade da doença.

As plantas mais velhas de eucalipto podem apresentar maior desfolha com a ação da mancha da mancha foliar. Graça (11) verificou que a intensidade de

Tabela 1. Incidência (\%) de mancha foliar causada por Cylindrocladium sp. /Kirramyces epicoccoides em progênies de Eucalyptus grandis, em Anhembi-SP e Itatinga-SP.

\begin{tabular}{|c|c|c|c|c|}
\hline \multirow{2}{*}{ Tratamentos } & \multicolumn{4}{|c|}{ Incidência (\%) } \\
\hline & 12 Meses & 24 Meses & 15 Meses & 27 Meses \\
\hline Progênies de $E$. grandis* & 96,7 & 99,5 & 96,8 & 99,9 \\
\hline Clone I 144 & 100 & 100 & 96,7 & 100 \\
\hline Sementes de E. grandis/Itatinga & 97,3 & 100 & 98,0 & 100 \\
\hline
\end{tabular}

*Médias da população formada com as 176 progênies de Eucalyptus grandis. 
Tabela 2. Severidade média de mancha foliar causada por Cylindrocladium sp./Kirramyces epicoccoides em progênies de Eucalyptus grandis, e das três testemunhas, em Anhembi-SP e Itatinga-SP, e a amplitude de variação nos valores.

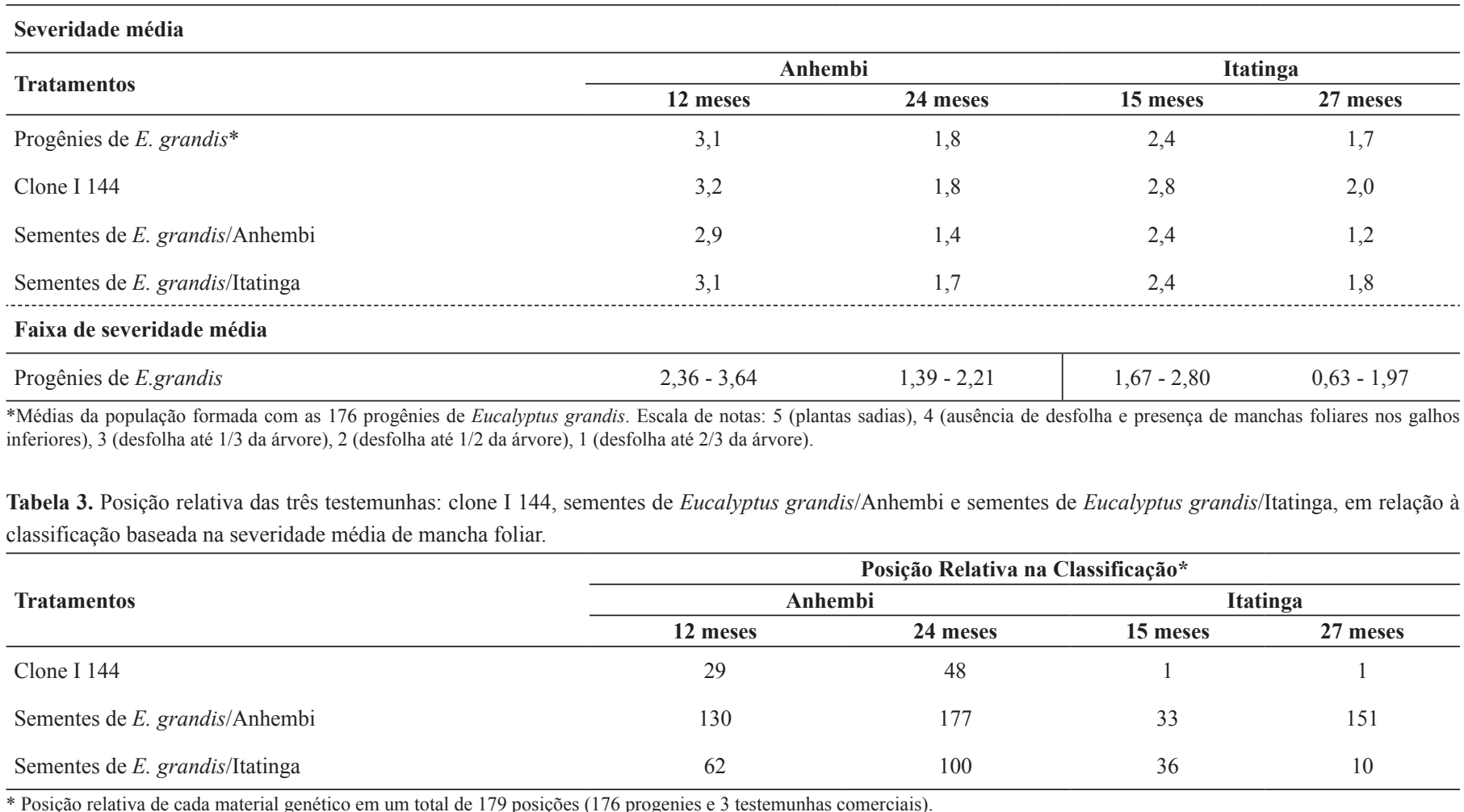

* Posição relativa de cada material genético em um total de 179 posições (176 progenies e 3 testemunhas comerciais).

desfolha causada pela mancha foliar de C. pteridis, em plantas em $E$. grandis $\mathrm{x} E$. urophylla foi significativamente maior em plantas mais velhas, plantas com 180 dias de idade, apresentaram desfolha média entre 36,8 e $40,6 \%$, enquanto que a desfolha média, em plantas dos mesmos clones com 120 dias de transplantio, foi entre 18,6 e 26,6\%, respectivamente. Plantas com 60 dias de idade não exibiram desfolha aos 50 dias após a inoculação.

Ao analisar a amplitude da severidade média das famílias e a posição do ranqueamento das testemunhas (Tabela 3), verificou-se que várias progênies obtiveram desempenho superior as testemunhas seminais de $E$. grandis com potencial para exploração da sua resistência em um programa de melhoramento. A exceção foi o clone I 144, em Itatinga, que se apresentou com a melhor colocação quando se considerou as duas avaliações.

Os resultados mostram o potencial das progênies de E. grandis em relação a resistência à mancha foliar. Várias progênies revelaram severidade média da doença menor que as testemunhas, exceto para o clone I144, em Itatinga, que foi o primeiro colocado no desempenho nas duas avaliações.

Assim, todas as progênies com desempenho superior às testemunhas apresentaram potencial para serem utilizadas como material genético de E. grandis com maior resistência à mancha foliar. Esses indivíduos que apresentaram a característica de resistência à mancha foliar, podem compor uma nova população para ser propagada, transmitindo uma proporção elevada de sua superioridade para esse caráter. $\mathrm{O}$ uso de plantas resistentes à mancha foliar pode promover menores perdas de produtividade, na ocorrência de surtos epidêmicos da doença em locais altamente favoráveis para o patógeno causar doença.

Com o aumento da severidade da mancha foliar o crescimento das árvores é afetado, de acordo com Alfenas et al. (2), quanto maior for à desfolha causada pela mancha foliar, menor será a área fotossintética da planta, e consequentemente maior será a redução na produtividade das plantas.

Os resultados dos testes teste de razão da verossimilhança indicam efeitos genéticos significativos em nível de progênies, em todas as avaliações e locais, exceto em Anhembi na segunda avaliação (Tabela 4). Pupin et al. (16) verificaram por meio do teste da razão de verossimilhança efeitos significativos para variável DAP em teste realizados com progênies de $E$. urophylla em Anhembi e Itatinga. Miranda et al., (15) também verificaram efeitos significativos em testes com progênies de E. grandis no estado de São Paulo para as variáveis altura, DAP e volume.

Tabela 4. Teste da razão da máxima verossimilhança para as variáveis resistência a mancha foliar em Anhembi primeira avaliação aos 12 meses e segunda aos 24 meses, e Itatinga aos 15 meses e 27 meses, respectivamente primeira e segunda avaliação.

\begin{tabular}{lcc}
\hline & \multicolumn{2}{c}{ LTR (Qui-quadrado) } \\
\cline { 2 - 3 } Local & $\mathbf{1}^{\text {a }}$ avaliação & $\mathbf{2}^{\text {a }}$ avaliação \\
\hline Anhembi & $31,61^{* *}$ & $0,03^{\text {ns }}$ \\
Itatinga & $80,14^{* *}$ & $19,78^{* *}$ \\
\hline
\end{tabular}

Nota: Valor do teste de Qui-quadrado com 1 grau de liberdade a $* 5 \%=3,84$ e a $* * 1 \%=$ $6,63,{ }^{\text {ns }}$ não significativo.

As progênies com desempenho superior podem ser selecionadas como material genético de E. grandis com maior resistência a mancha foliar. A seleção de indivíduos nas famílias selecionadas poderá formar uma nova população-base, visando avanços no melhoramento genético deste caráter. Assim, todas as progênies com desempenho superior às testemunhas apresentaram potencial para serem utilizadas como material genético de $E$. grandis com maior resistência à mancha foliar. 


\section{REFERÊNCIAS}

1. Alfenas, A.C.; Ferreira, F.A.; Mafia, R.G.; Gonçalves, R.C. Isolamento de fungos fitopatogênicos. In: Alfenas, A.C.; Mafia, R.G. Métodos em fitopatologia. Viçosa, MG: Editora UFV, 2007. p.53-90.

2. Alfenas, A.C.; Zauza, E.A.V.; Mafia, R.G.; Assis, T.F. Clonagem e doenças do eucalipto. 2.ed. Viçosa, MG: Editora UFV, 2009. 500p.

3. Alvares, C. A.; Stape, J. L.; Sentelhas, P. C.; Gonçalvez, J. L. M.; Sparoa vek, G. Koppen's climate classification map for Brazil. Meteorologische Zeitschrift, Stuttgart v.22, n.6, p. 711-728, 2014.

4. Amorim, L.; Bergamin Filho, A. Fenologia, patometria e quantificação de danos. In: Amorim, L.; Bergamin Filho, A.; Rezende, J.A.M. (Ed.). Manual de fitopatologia: princípios e conceitos. 4.ed. São Paulo: Agronômica Ceres, 2011. p.517-540.

5. Auer, C.G.; Santos, A.F.; Furtado, E.L. Doenças do eucalipto. In: Amorim, L.; Rezende, J.A.M.; Bergamin Filho, A.; Camargo, L.E.A. Manual de fitopatologia. 5.ed. Ouro Fino: Agronômica Ceres, 2016. v.2, p.359-372.

6. Barnett, H.L.; Hunter, B.B. Illustrated genera of imperfect fungi. 3.ed. New York: MacMillan, 1972. 241p.

7. Brown, B.N.; Ferreira, F.A. Disease during propagation of eucalypts. In: Keane, P.J.; Kile, G.A.; Podger, F.D.; Brown, B.N. (Ed.). Disease and pathogens of Eucalypts. Camberra: CSIRO Publishing, p. 119-151, 2000.

8. Camargo, L.E.A. O cancro do eucalipto causado por Cryphonectria cubensis: sua dinâmica, quantificação e perdas avaliadas em um plantio de Eucalyptus grandis. 1989. 98f. Dissertação (Mestrado em Agronomia) - Escola Superior de Agricultura "Luiz de Queiroz", Universidade de São Paulo, Piracicaba.

9. Ferrari, M.P.; Couto, H.T.Z. Avaliação de perdas em rendimento de madeie ras devido ao cancro do Eucalyptus causado por Cryphonectria cubensis (Bruner) Hodges. Revista IPEF, Piracicaba, n.27, p.9-15, 1984.

10. Ferreira, F.A. Patologia florestal: principais doenças florestais no Brasil. Viçosa, MG: SIF, 1989. 570p.

11. Graça, R.N. Penetração e condições favoráveis para penetração de Cylindrocladium pteridis. 2007. 38f. Dissertação (Mestrado em Fitopatologia) - Universidade Federal de Viçosa, Viçosa.

12. Indústria Brasileira de Árvores. Relatório IBÁ. São Paulo, 2017. 80p.

13. Krugner, T.L.; Guerrini, I.A.; Auer, C.G. Surto epidêmico da mancha foliar causada por Cylindrocladium sp. e sua relação com o crescimento de espécies/procedências de Eucalyptus na região de Tucuruí, PA. Revista IPEF, Piracicaba, n.43/44, p.74-78, 1990.

14. Lippert, D.B.; Benedetti, A.C.P.; Muniz, M.F.B.; Pereira, R.S.; Biernaski Junior, C.A.; Finkenauer, E.; Berra, E.F. Comportamento espectral de folhas de Eucalyptus globulus (Labill.) atacadas por Mycosphaerella spp. nas regiões do visível e do infravermelho próximo do espectro eletromagnético. Ciência Florestal, Santa Maria, v.25, n.1, p.211-219, 2015.

15. Miranda, A.C.; Moraes, M.L.T.; Silva, P.H.M.; Sebbenn, A.M. Ganhos genéticos na seleção pelo método do índice multiefeitos em progênies polinização livre de Eucalyptus grandis Hill ex Maiden. Scientia Forestalis, Piracicaba, v. 43, n. 105, 2015.

16. Pupin, S.; Santos, A.V.A.; Zaruma, D.U.G.; Miranda, A.C.; Silva, P.H.M.; Marino, C.L.; Sebbenn, A.M.; Moraes, M.L.T. Produtividade, estabilidade e adaptabilidade em progênies de polinização aberta de Eucalyptus urophylla S.T. Blake. Scientia Forestalis, Piracicaba, v. 43, n. 105, p. 127-134, 2015

17. RESENDE, M. D. V. Matemática e estatística na análise de experimentos e no melhoramento genético. Colombo: Embrapa Florestas, 2007. 362 p.

18. Resende, M.D.V. Software Selegen-REML/BLUP: a useful tool for plant breeding. Crop Breeding and Applied Biotechnology, Viçosa, v.16, n.4, p.3330-339, 2016.

19. Schultz, B. Levantamento de doenças bióticas e abióticas em Eucalyptus benthamii Maiden nos estados do Paraná e Santa Catarina. 2011. 101f. Dissertação (Mestrado em Engenharia Florestal) - Universidade Federal do Paraná, Curitiba.

20. Schultz, B.; Sbravatti Junior, J.A.; Auer, C.G.; Santos, A. F. dos. Impacto da mancha foliar causada por Cylindrocladium candelabrum em plantios jovens de Eucalyptus benthamii em Rio Negrinho-SC. Ciência Florestal, Santa Maria, v.25, p.307-316, 2015.

21. Serviço de Estações Experimentais. Piracicaba: Universidade de São Paulo, 2017. Disponível em: $<$ http://www.esalq.usp.br/svee/apresentacao $>$. Acesso em: 22 fev.2017.

22. Silva, P. H. M.; Miranda, A. C.; MORAES, M. L. T.; Edson L.Furtado, E. L.; Stapee, J. L.; Alvares, C. A.; Sentelhas, P. S.; Mori, E, S.; Sebbenng, A. M. Selecting for rust (Puccinia psidii) resistance in Eucalyptus grandis in São Paulo State, Brazil. Forest Ecology and Management, v.303, n.1, p. 91-97, 2013 .

23. Sturion, J. A.; Resende, M. D. V. Avaliação genética e análise de deviance em um teste desbalanceado de procedência e progênie de Ilex paraguariensis. Pesquisa Florestal Brasileira, Colombo, v.30, n.62, p.157-160, 2010.

24. Taole, M.M.; Burgess, T.I.; Gryzenhout, M.; Wingfield, B.D.; Wingfield, M.J. DNA sequence incongruence and inconsistent morphology obscure species boundaries in the Teratosphaeria suttonii species complex. Mycoscience, Tokyo, v.53, n.4, p.270-283, 2012.

25. Tejedor, C.; Pérez, S.; Renedo, C.J.; Ortiz, A.; Mañana, M.; Silió, D Energy implications of the Mycosphaerella sp. in Eucalyptus globulus stands. Renewable Energy and Power Quality Journal, Vigo, v.6, n.1, p.809-812, 2008 . 